\section{FeNO monitoring to adjust treatment in asthma: has it come of age?}

\author{
Dominick E Shaw
}

Asthma guidelines around the world urge healthcare professionals to use the lowest dose of inhaled corticosteroid (ICS) to achieve asthma control, normally defined as achievement of best lung function, reduction in symptoms and reduction of future exacerbation risk. ${ }^{1}$ At first glance, this approach seems sensible. Long-term ICS use has appreciable side effects and there is evidence that targeting symptoms with increased ICS doses results in improved outcomes. This approach already forms the backbone of the budesonide/formoterol or beclometasone/ formoterol as maintenance and reliever therapy (SMART/FMART), and more recently quadrupling ICS doses during a period of worsening symptoms has been shown to lead to improved outcomes in adults. $^{2}$

However, life is rarely that simple. One of the main physiological effects of ICS, reduced eosinophilic airway inflammation, is not firmly linked to key asthma parameters namely variable airflow obstruction, airway hyper-responsiveness and symptoms. ${ }^{3}$ This heterogeneity in asthma mechanisms and a call to redefine how we classify airway disease, is well covered in the recent Lancet Commissions article. In this article, the authors suggest that ICS treatment is not escalated unless biomarkers of type 2 inflammation are increased. ${ }^{4}$ The two most readily available biomarkers are blood or sputum eosinophil counts and the fraction of nitric oxide in exhaled breath (FeNO). ${ }^{5}$

With this in mind, Petsky and colleagues ${ }^{6}$ enter the arena with a systematic review and meta-analysis of tailoring asthma treatment on markers of eosinophilic inflammation. They synthesised the evidence from 3 Cochrane reviews and 22 randomised controlled studies, across a range of patient populations, where asthma treatment was tailored using FeNO or sputum eosinophil counts and outcomes compared with a control population. The main outcome was asthma exacerbations as defined by the individual study authors, but mostly referring to a new course of oral corticosteroids

Correspondence to Professor Dominick E Shaw, Respiratory Research Unit, University of Nottingham, Nottingham NG7 2RD, UK;

dominic.shaw@nottingham.ac.uk (although some papers included antibiotics too).

Pestky et al found that participants randomised to the FeNO strategy were significantly less likely to have exacerbations when compared with participants managed by a control strategy. The numbers for adults were $\mathrm{OR}=0.60(95 \% \mathrm{CI} 0.43$ to 0.84 ) and for children 0.58 (95\% CI 0.45 to 0.75$)$. Using sputum eosinophil counts as a guide to ICS therapy the numbers were similar: $\mathrm{OR}=0.36$ (95\%CI 0.21 to 0.62$)$. However, there were no significant group differences for either strategy on daily ICS dose at the end of the study, asthma control or lung function. Unfortunately, the potentially more meaningful total ICS exposure over the study (area under the curve) could not be calculated. Based on their data, the authors conclude that 'at present, despite their popularity, there is insufficient evidence to advocate their use (sputum eosinophils or $\mathrm{FeNO}$ ) in routine clinical practice'. Some readers may be surprised by this, given the reduction in exacerbations presented, so how does this statement fit with current guidance?

In April 2014, NICE (England's National Institute for Health and Care Excellence) recommended the use of FeNO as an option to help diagnose asthma in adults and children and to support asthma management in people who were symptomatic despite using ICS. No specific cut points were given for FeNO-based management (diagnosis or dose titration). The review identified four studies; cut-offs for the highest sum of sensitivity and specificity for diagnosis ranged from $20 \mathrm{ppb}$ to $47 \mathrm{ppb}$ for FeNO. Sensitivities ranged from $32 \%$ to $88 \%$, and specificities from $75 \%$ to $93 \%$. Consequently the External Assessment Group at NICE concluded that it was difficult to identify the optimal cut-off for sensitivity and specificity of FeNO; however, its general use was recommended.

In November 2017, NICE published further guidance on the diagnosis, monitoring and chronic asthma management. This recommended using a FeNO of $40 \mathrm{ppb}$ or more in adults, and $35 \mathrm{ppb}$ or more in children or young people, to help diagnose asthma. It stated against using FeNO to monitor asthma control but referred back to the previous 2014 guideline for supporting asthma management in people who were still symptomatic despite appropriate ICS use.

Given the recommendations from NICE, where does this leave FeNO as a tool for titrating ICS dose in asthma? A reduction in exacerbations is an important outcome, and as this latest meta-analysis shows, this can be achieved using FeNO measurements to guide therapy. Reducing exposure to a potentially toxic treatment (oral corticosteroids) is important for our patients and it is one of the main criteria used by payers to assess cost effectiveness of asthma interventions. The finding of a lack of efficacy on lung function or asthma control does fit with the paradigm that symptoms and inflammation are not always in step and should therefore not predicate against the use of FeNO. The lack of reduction in overall ICS dose is also not a major concern; presumably the increased dose of ICS in those with high FeNO is counterbalanced by a reduction in those with a low FeNO. Furthermore, FeNO meets many requirements for routine clinical use (standardised, easy to preform, relatively cheap, repeatable).

The key issue is therefore cut points for FeNO. Hard cut points for titrating treatment (up or down) have not yet been reliably identified. There are several reasons for this. FeNO has traditionally been used as marker of eosinophilic inflammation, but it does not have a direct causal relationship and may better reflect interleukin 13 activity as seen in the studies of Lebrikuzimab. ${ }^{7}$ This is also clearly seen in the studies of Mepolizumab where both blood and sputum eosinophil counts were reduced by therapy, but FeNO did not alter. ${ }^{9}$ Second as can be seen from the fact that NICE recommend different cut points based on age, one FeNO cut point does not fit all. Normal ranges have been established and they vary based on age, gender, atopy and smoking. ${ }^{10} 11$ Lastly, the study design and consequent external validity of FeNO studies depends greatly on the control algorithm used. If the control algorithm is set too rigidly, or varies from routine care (ie, attempting to achieve perfect lung function, no symptoms and no rescue short acting beta agonist use at all visits), the control arm is at risk of overtreatment. Although the aim for perfect control is admirable, often some compromise has to be accepted in the real world. Standardising control arms (or using an agreed standard of care) in interventional asthma studies would help study comparison and future meta-analysis. Indeed there is already some evidence for overtreatment; one study found a $348 \mathrm{mcg}$ reduction ( $25 \%$ of total daily dose) was 
achievable with no difference in annual dose of oral corticosteroids, ${ }^{12}$ although patients with well-controlled asthma who stop regular low-dose ICS have an increased risk of an asthma exacerbation compared with those who continue. ${ }^{13}$

There are other considerations when titrating treatment in people with asthma. The evidence that there is a clear dose response relationship between clinical response and treatment dose is mixed; indeed this relationship may plateau above the equivalent of $1000 \mathrm{mcg}$ BDP. ${ }^{14}$ Furthermore, the dose response relationship between FeNO reduction and increasing ICS dose is flat between $100 \mathrm{mcg}$ and $800 \mathrm{mcg}$, with no significant changes in FeNO between these doses. ${ }^{15}$ FeNO levels may be elevated for other reasons, especially nasal polyposis, ${ }^{16}$ therefore treating the biomarker, and not the patient, may be unwise. Stepping down treatment based on stable FeNO levels to identify those at risk of deterioration has also been attempted; Wilson et al assessed whether a low baseline FeNO predicted successful ICS dose reduction or whether an increase in FeNO following dose reduction predicted deterioration. Neither approach was helpful. ${ }^{17}$

Although there are interesting data emerging on the use of FeNO to assess compliance to ICS therapy, ${ }^{18}$ and to predict response to therapy, irrespective of a label of asthma, ${ }^{19}$ the key question of how best to use FeNO measurements to uptitrate or downtitrate ICS dosing remains. Given the heterogeneity of asthma, allied to the individual versus group mean response to treatment, ${ }^{20}$ what is required is personalised cut points based on an individual's FeNO response to initial ICS therapy, with identification of specific cut points for that individual, followed by regular monitoring and treatment escalation based on
FeNO variation. Until then, although we know FeNO tells us something important about an individual's response to ICS, we will be unable to fully understand exactly what.

Funding The authors have not declared a specific grant for this research from any funding agency in the public, commercial or not-for-profit sectors.

Competing interests None declared.

Patient consent Not required.

Provenance and peer review Commissioned; internally peer reviewed.

(C) Author(s) (or their employer(s)) 2018. No commercial re-use. See rights and permissions. Published by BMJ.

\section{Check for updates}

To cite Shaw DE. Thorax 2018:73:1095-1096.

Accepted 23 July 2018

Published Online First 12 August 2018

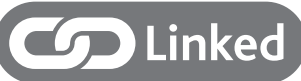

http://dx.doi.org/10.1136/thoraxjnl-2018-211540

Thorax 2018;73:1095-1096.

doi:10.1136/thoraxjnl-2018-211761

\section{REFERENCES}

1 Global Initiative for Asthma. GINA report, global strategy for asthma management and prevention, 2017.

2 McKeever T, Mortimer K, Wilson A, et al. Quadrupling inhaled glucocorticoid dose to abort asthma exacerbations. N Engl J Med 2018;378:902-10.

3 Tattersfield AE, Postma DS, Barnes PJ, et al. Exacerbations of asthma: a descriptive study of 425 severe exacerbations. The FACET International Study Group. Am J Respir Crit Care Med 1999;160:594-9.

4 Pavord ID, Beasley R, Agusti A, et al. After asthma: redefining airways diseases. Lancet 2018;391:350-400

5 Pavord ID, Shaw DE, Gibson PG, et al. Inflammometry to assess airway diseases. Lancet 2008;372:1017-9.

6 Petsky HL, Cates CJ, Kew KM, et al. Tailoring asthma treatment on eosinophilic markers (exhaled nitric oxide or sputum eosinophils): a systematic review and meta-analysis. Thorax. Published Online First: 1 Jun 2018.:doi:10.1136/thoraxjnl-2018-211540.

7 Robinson D, Humbert M, Buhl R, et al. Revisiting Type 2-high and Type 2-low airway inflammation in asthma: current knowledge and therapeutic implications. Clin Exp Allergy 2017;47:161-75.

8 Corren J, Lemanske RF, Hanania NA, et al. Lebrikizumab treatment in adults with asthma. $N$ Engl J Med 2011;365:1088-98.

9 Haldar P, Brightling CE, Hargadon B, et al. Mepolizumab and exacerbations of refractory eosinophilic asthma. N Eng/ J Med 2009;360:973-84.

10 Torén K, Murgia N, Schiöler L, et al. Reference values of fractional excretion of exhaled nitric oxide among non-smokers and current smokers. BMC Pulm Med 2017;17:118.

11 Jacinto T, Malinovschi A, Janson C, et al. Evolution of exhaled nitric oxide levels throughout development and aging of healthy humans. J Breath Res 2015:9:036005

12 Hawkins G, McMahon AD, Twaddle S, et al. Stepping down inhaled corticosteroids in asthma: randomised controlled trial. BMJ 2003;326:1115

13 Rank MA, Hagan JB, Park MA, et al. The risk of asthma exacerbation after stopping low-dose inhaled corticosteroids: a systematic review and meta-analysis of randomized controlled trials. J Allergy Clin Immunol 2013;131:724-9.

14 Lipworth BJ. Airway and systemic effects of inhaled corticosteroids in asthma: dose response relationship. Pulm Pharmacol 1996:9:19-27.

15 Silkoff PE, McClean P, Spino M, et al. Dose-response relationship and reproducibility of the fall in exhaled nitric oxide after inhaled beclomethasone dipropionate therapy in asthma patients. Chest 2001;119:1322-8.

16 Galli J, Montuschi P, Passàli GC, et al. Exhaled nitric oxide measurement in patients affected by nasal polyposis. Otolaryngol Head Neck Surg 2012;147:351-6.

17 Wilson E, McKeever T, Hargadon B, et al. Exhaled nitric oxide and inhaled corticosteroid dose reduction in asthma: a cohort study. Eur Respir J 2014;44:1705-7.

18 McNicholl DM, Stevenson M, McGarvey LP, et al. The utility of fractional exhaled nitric oxide suppression in the identification of nonadherence in difficult asthma. Am J Respir Crit Care Med 2012;186:1102-8.

19 Martin MJ, Wilson E, Gerrard-Tarpey W, et al. The utility of exhaled nitric oxide in patients with suspected asthma. Thorax 2016;71:562-4.

20 Malmstrom K, Rodriguez-Gomez G, Guerra J, et al. Oral montelukast, inhaled beclomethasone, and placebo for chronic asthma. A randomized, controlled trial. Montelukast/Beclomethasone Study Group. Ann Intern Med 1999:130:487-95. 